\title{
Finding inward rectifier channel inhibitors: why and how?
}

\section{Marcel A. G. van der Heyden*}

Division Heart and Lungs, Department of Medical Physiology, University Medical Center, Utrecht, Netherlands

${ }^{*}$ Correspondence: m.a.g.vanderheyden@umcutrecht.nl

\section{A commentary on}

Discovery, characterization, and structure-activity relationships of an inhibitor of inward rectifier potassium (Kir) channels with preference for Kir2.3, Kir3.X, and Kir7.1

by Raphemot, R., Lonergan, D. F., Nguyen, T. T., Utley, T., Lewis, L. M., Kadakia, R., Weaver, C. D., Gogliotti, R., Hopkins, C., Lindsley, C. W., and Denton, J. S. (2011). Front. Pharmacol. 2:75. doi: 10.3389/ fphar.2011.00075

The eukaryotic inward rectifier potassium (Kir) channel family is part of an ancient class of ion channels evolved in prokaryotes (Durell and Guy, 2001). Kir proteins have two transmembrane domains encompassing the pore loop region. Subunit tetramerization, either homo- or hetero-typic, results in the formation of a functional channel. The 16 known mammalian Kir channel proteins are divided over seven different families, each having their own specific expression pattern and functional characteristics (De Boer et al., 2010; Hibino et al., 2010). In general, Kir channels allow more inward potassium flow at membrane potentials negative from the potassium equilibrium potential $\left(E_{\mathrm{K}}\right)$ than outward flow at equivalent membrane potentials positive of $E_{\mathrm{K}}$, a characteristic known as inward rectification. Within the superfamily, strong and weak rectifiers exist. Strong rectifying channels are most apparent in excitable tissues, where they are responsible for a stable and negative resting membrane potential, and due to their strong rectification, prevent extensive potassium loss during action potential formation. Weak rectifiers are expressed in numerous other tissue types and organs and have a role in processes like potassium homeostasis, insulin release, and signal transduction. Despite the long evolutionary history only a few inhibitors are known, of which most show limited specificity at their best. One of the most widely used Kir inhibitors is $\mathrm{Ba}^{2+}$. However, as it blocks all Kir chan- nels at concentrations differing not even two orders of magnitude, its severe effects in whole animal studies or poisoning cases are difficult to ascribe to a given Kir family member (De Boer et al., 2010). Given the fact that most cell types express more than one Kir channel protein, lack of specific inhibitors therefore strongly hinders our understanding of their contribution and working mechanism in normal physiology and pathology. The presence of disease causing mutations in human Kir channels that lead to severe syndromes, e.g., Bartter's syndrome (Kir1.1), Andersen Tawil syndrome (Kir2.1), SeSAME syndrome (Kir4.1), neonatal diabetes (Kir6.2), Snowflake vitreoretinal degeneration (Kir7.1) illustrate their importance in human pathology, while many more milder Kir related channelopathies probably remain unaccounted for at this moment. An excellent illustration of the potential of inward rectifier channel inhibitors comes from the field of neonatal diabetes where recognition of disease causing gain-of-function mutations in Kir6.2 (Gloyn et al., 2004) and its regulatory subunit Sur1 (Ellard et al., 2007) provided new insights to treat the disease with Kir6/Sur inhibitors (Pearson et al., 2006). One of the diseases that affects significant numbers of the aging human population, and has been correlated to Kir2.X and Kir3.X dysfunction, is atrial fibrillation. Increased Kir channel activity in the atria shortens atrial action potential durations and thereby allows formation of multiple re-entry circuits in the atrial tissue fueling rapid arrhythmia. Furthermore, ventricular Kir2.1 overexpression in mice results in rotor driven tachycardia's. These mechanisms are likely to have a role in initiation and perpetuation of the process of atrial fibrillation. Therefore, pharmacological intervention by means of Kir channel modifying drugs may be a new and valuable treatment option in this disease (Ehrlich, 2008).

Standard single cell patch clamp methods allow highly detailed characterization of the inhibiting capacity and its underlying mechanisms of new compounds for virtually every ion channel of interest, including Kir channels. However, procedures are time consuming and therefore not compatible with large screening procedures. Automated patching techniques to a large extent overcome these throughput limitations (Dunlop et al., 2008). Alternatively, the last decade, a number of non-electrophysiological Kir assay systems have been developed that allow large scale screening assays also. Systems are either based on membrane potential sensitive dyes (e.g., Walsh, 2011) or thallium flux (e.g., Niswender et al., 2008). The latter makes use of a thallium sensitive fluorescent probe loaded into Kir expressing cells. Upon stimulation of channel opening, thallium from the bath medium enters the cell through Kir channels, resulting in increased fluorescence. Co-application of different test compounds to the bath medium than enables identification of potent Kir channel inhibitors, and dependent on the assay conditions, activators. New lead compounds for every Kir class will likely be derived from screening efforts of public, academic, or private owned compound libraries (e.g., Wang et al., 2011), or from development of existing drugs displaying Kir channel block as an apparent side effect (Van der Heyden and Sánchez-Chapula, 2011).

In this issue of Frontiers in Pharmacology of Ion Channel and Channelopathies, Raphemot et al. (2011) describe the results from a screen for compounds that can inhibit Kir3.X channels. For this purpose, they used a thallium flux assay in combination with a compound library originally used for discovery of new Kir1.1 inhibitors. They identified a lead compound, named VU573 that besides blocking Kir3.X, also demonstrate specificity for Kir2.3 channels over Kir2.1. Subsequent cross validation using patch clamp assays in Xenopus oocytes and HEK293 cells reached similar conclusions. However, VU573 showed also inhibiting action on Kir7.1. Next, making clever use of a Kir7.1 mutant, they developed and validated a Kir7.1 thallium flux assay, 
and in combination with a medicinal chemistry approach, this yielded a VU573 analog that lost affinity for Kir7.1 and Kir1.1, but retained reasonable inhibition of Kir3.X and Kir2.3. This makes an interesting combination from the perspective of atrial fibrillation therapy, since Kir3.1/3.4 and Kir2.3 are predicted channels involved in atrial fibrillation (Ehrlich, 2008) as mentioned before.

New questions are arising now. What is the nature of Kir inhibition by VU573? As pointed out by the authors, drugs can directly plug the channel pore inhibiting potassium flow, interfere with lipid [i.e., phosphatidylinositol 4,5-bisphosphate $\left(\mathrm{PIP}_{2}\right)$ ] dependent Kir activation or both. The preference of VU573 for Kir2.3 over Kir2.1 might indicate a role for PIP interference, but extensive studies using channel structure models, Kir mutations affecting $\mathrm{PIP}_{2}$ binding, and application of $\mathrm{PIP}_{2}$ during patch clamp experiments are required first to answer this intriguing question. Secondly, what is the long term effect of VU573 or its derivatives on ion channel trafficking? An increasing number of drugs, regardless whether they block the channel directly, affect channel protein trafficking resulting in decreased amounts of functional channels on the plasma membrane which may pose an arrhythmogenic risk (Van der Heyden et al., 2008). Thirdly, is a combined Kir3.X and Kir2.3 block effective indeed against atrial fibrillation without affecting ventricular electrophysiological parameters? Dedicated in vitro and in vivo models are essential here to answers these questions.

The data reported by Raphemot et al. (2011) are another step in the development of subtype specific $I_{\mathrm{K} 1}$ modifiers that eventually will provide valuable insights into the roles of $I_{\mathrm{K} 1}$ in normal physiology and may offer clinicians new treatment options for a diverse set of genetic syndromes and acquired diseases.

\section{ACKNOWLEDGMENTS}

I thank Dr. T. P. de Boer for careful reading of the manuscript. This work was supported by a grant from the Dondersfonds (Utrecht, The Netherlands).

\section{REFERENCES}

De Boer, T. P., Houtman, M. J. C., Compier, M., and Van der Heyden, M.A. G. (2010). The mammalian KIR2.x inward rectifier ion channel family: expression pattern and pathophysiology. Acta Physiol. (Oxf.) 199, 243-256.

Dunlop, J., Bowlby, M., Peri, R., Vasilyev, D., and Arias, R. (2008). High-throughput electrophysiology: an emerging paradigm for ion-channel screening and physiology. Nat. Rev. Drug Discov. 7, 358-368.

Durell, S. R., and Guy, H. R. (2001). A family of putative Kir potassium channels in prokaryotes. BMC Evol. Biol. 1, 14. doi: 10.1186/1471-2148-1-14

Ehrlich, J. R. (2008). Inward rectifier potassium currents as a target for atrial fibrillation therapy. J. Cardiovasc. Pharmacol. 52, 129-135.

Ellard, S., Flanagan, S. E., Girard, C. A., Patch, A. M., Harries, L. W., Parrish, A., Edghill, E. L., Mackay, D. J., Proks, P., Shimomura, K., Haberland, H., Carson, D. J., Shield, J. P., Hattersley, A. T., and Ashcroft, F. M. (2007). Permanent neonatal diabetes caused by dominant, recessive, or compound heterozygous SUR1 mutations with opposite functional effects. Am. J. Hum. Genet. 81, 375-382.

Gloyn, A. L., Pearson, E. R., Antcliff, J. F., Proks, P., Bruining, G. J., Slingerland, A. S., Howard, N., Srinivasan, S., Silva, J. M., Molnes, J., Edghill, E. L. Frayling, T. M., Temple, I. K., Mackay, D., Shield, J. P., Sumnik, Z., Van Rhijn, A., Wales, J. K., Clark, P., Gorman, S., Aisenberg, J., Ellard, S., Njølstad, P. R., Ashcroft, F. M., and Hattersley, A. T. (2004). Activating mutations in the gene encoding the ATP-sensitive potassium-channel subunit Kir6.2 and permanent neonatal diabetes. N. Engl. J. Med. 350, 1838-1849.

Hibino, H., Inanobe, A., Furutani, K., Murakami, S., Findlay, I., and Kurachi, Y. (2010). Inwardly rectifying potassium channels: their structure, function, and physiological roles. Physiol. Rev. 90, 291-366.

Niswender, C. M., Johnson, K. A., Luo, Q., Ayala, J. E., Kim, C., Conn, P. J., and Weaver, C. D. (2008). A novel assay of $\mathrm{Gi} / \mathrm{o}$-linked $\mathrm{G}$ protein-coupled receptor coupling to potassium channels provides new insights into the pharmacology of the group III metabotropic glutamate receptors. Mol. Pharmacol. 73, 1213-1224. Pearson, E. R., Flechtner, I., Njølstad, P. R., Malecki, M. T., Flanagan, S. E., Larkin, B., Ashcroft, F. M., Klimes, I., Codner, E., Iotova, V., Slingerland, A. S., Shield, J., Robert, J. J., Holst, J. J., Clark, P. M., Ellard, S., Søvik, O., Polak, M., Hattersley, A. T., and Neonatal Diabetes International Collaborative Group. (2006). Switching from insulin to oral sulfonylureas in patients with diabetes due to Kir6.2 mutations. N. Engl. J. Med. 355, 467-477.

Van der Heyden, M. A. G., and Sánchez-Chapula, J. A. (2011). Toward specific cardiac IK1 modulators for in vivo application: old drugs point the way. Heart Rhythm 8, 1076-1080.

Van der Heyden, M. A. G., Smits, M. E., and Vos, M. A. (2008). Drugs and trafficking of ion channels: a new pro-arrhythmic threat on the horizon? Br. J. Pharmacol. 153, 406-409.

Walsh, K. B. (2011). Targeting GIRK channels for the development of new therapeutic agents. Front. Pharmacol. 2:64. doi: 10.3389/fphar.2011.00064

Wang, H. R., Wu, M., Yu, H., Long, S., Stevens, A., Engers, D. W., Sackin, H., Daniels, J. S., Dawson, E. S., Hopkins, C. R., Lindsley, C. W., Li, M., and McManus, O. B. (2011). Selective inhibition of the Kir2 family of inward rectifier potassium channels by a small molecule probe: the discovery, SAR, and pharmacological characterization of ML133. ACS Chem. Biol. 6, 845-856.

Received: 11 November 2011; accepted: 23 December 2011; published online: 09 January 2012.

Citation: van der Heyden MAG (2012) Finding inward rectifier channel inhibitors: why and how? Front. Pharmacol. 2:95. doi: 10.3389/fphar.2011.00095

This article was submitted to Frontiers in Pharmacology of Ion Channels and Channelopathies, a specialty of Frontiers in Pharmacology.

Copyright (C) 2012 van der Heyden. This is an open-access article distributed under the terms of the Creative Commons Attribution Non Commercial License, which permits noncommercial use, distribution, and reproduction in other forums, provided the original authors and source are credited. 